\title{
Implications of Human Genome Research: Impact on Graduate Education in Genetic Counseling
}

\author{
Barbara Bowles Biesecker, ${ }^{1,4}$ Catherine Walsh Vockley, ${ }^{2}$ \\ and Elizabeth Conover ${ }^{3}$
}

\begin{abstract}
A conference of genetic counseling and clinical nurse specialist graduate program directors was hosted by the National Society of Genetic Counselors and funded by the Ethical, Legal, and Social Implications Program of the National Center for Human Genome Research in June 1992. One aspect of the conference addressed implications of the Human Genome Initiative for graduate education in genetic counseling. Within this paper, the topics of human variation and diversity, genetic discrimination, issues in nondirectiveness, and genetic screening and policy development are reviewed and recommendations made for graduate curricula development and enhancement. In addition, suggestions are included for practicing genetic counselors.
\end{abstract}

KEY WORDS: genetic counseling graduate curricula; human genome implications; nondirectiveness; genetic discrimination; genetic screening; human diversity.

\section{INTRODUCTION}

The practice of genetic counseling is burgeoning as a consequence of the rapid developments in human molecular genetics. There are significant social and individual implications of this new technology. Most often, the education and counseling accompanying testing is provided by genetic counselors, as they support patients in the decision-making process regarding

${ }^{1}$ Department of Molecular Medicine and Genetics and the Human Genome Center, University of Michigan, Ann Arbor, Michigan.

${ }^{2}$ Department of Medical Genetics, Mayo Clinic and Mayo Foundation, Rochester, Minnesota. ${ }^{3}$ Meyer Rehabilitation Institute, University of Nebraska Medical Center, Omaha, Nebraska.

${ }^{4}$ Correspondence should be directed to Barbara Bowles Biesecker, 2570B MSRBII Box 0674, University of Michigan, Department of Internal Medicine, Ann Arbor, Michigan 48109-0674. 
testing and help them to cope with the outcome. Counselors also play a role in determining how new genetic information and technology will be used. It is essential that genetic counseling graduate education curricula reflect changes in knowledge and technology during this new era of human genome research. Curricula should teach students to appreciate the technical advances and stimulate them to actively participate in efforts to address the social, psychological, and ethical implications that will affect the community.

In June 1992, a two and one-half day conference of genetic counseling and clinical nurse specialist graduate training program directors was hosted by the National Society of Genetic Counselors and funded by the Ethical, Legal, and Social Implications Program of the National Center for Human Genome Research. One of three themes of the conference addressed implications of the human genome initiative. This theme was divided into four more specific subtopics; human variation and diversity, genetic discrimination, potential new threats to non-directiveness, genetic screening, and policy development. Herein these topics are reviewed along with conference participant recommendations for graduate genetic counseling curricula development and enhancement.

Many issues relevant to genetic counseling students are also pertinent to practicing counselors. Discussion of recommendations for graduate curricula resulted in parallel suggestions for the profession at large.

\section{HUMAN VARIATION AND DIVERSITY}

\section{Background Discussion}

Knowledge of genetic make-up affects individuals' assessments of their own health and self-concept. This includes how people view themselves as like or unlike others. Personal traits, even personality characteristics, are often attributed to genes. This notion of genetic determinism is condoned by the media and socially reinforced (Nelkin, 1993). The outcome of the Human Genome Initiative will only amplify these issues as more genetic testing information becomes available. Although all individuals carry deleterious genes, human characteristics are determined by a complex interaction of environmental and genetic factors. The public perception of genetic determinism is thereby distorted and suggests great need for accurate and widespread public education.

In the future it will be possible to determine large amounts of an individual's genetic make-up. Physicians or third-party payers of health care may require or encourage determination and dissemination of this information. This may affect how people view themselves as healthy or 
normal. Genetic counselors play an important role in teaching the value of human variation in a society that fears difference and discriminates based on it.

Genetic counselors also function as gatekeepers for genetic testing. The long-held principle of non-directiveness in genetic counseling is being challenged as we move into an era in which genetic technology may be developed to test for traits or characteristics. The principle of non-directiveness will need to be re-evaluated in view of such developments. For example, it may be appropriate for counselors to refuse to offer certain tests. Genetic counseling students should be encouraged to think critically about these issues. Genetic counselors should explore their role in making certain new testing available. Also, genetic counselors need to play a role in establishing social policy and/or legislation to address the use of testing.

An example of this issue is fetal sex selection, which continues to be a pertinent public concern (Jones, 1992). A majority of genetic counselors surveyed indicated that they would offer sex selection to their patients; the reason most often cited was that clients should be allowed to make autonomous decisions regarding childbearing (Wertz, 1988). This suggests that counselors believe the principle of non-directiveness outweighs judgment of the burden of any trait. Are there going to be prenatal tests that challenge the principle further, such as tests for homosexuality, learning disabilities, or short(er) stature? Counselors will have to reconcile these issues with the legal availability of abortion (for any reason) and the reproductive freedom position statement of the National Society of Genetic Counselors (NSGC).

As the testing for traits becomes profitable, laboratories will market these tests to obstetricians and the public. How much control will genetic counselors have over the use of tests and the manner in which they are offered to patients? It is likely that genetic counseling practice will be altered by these influences. Genetic testing will shift from academic and private genetic centers into primary care practice and other medical settings. In this newer mode of service delivery, genetic counselors may have less influence over test utilization.

\section{Recommendations for Curricula Enhancement}

1. Seminar discussions of control over access to testing, how such decisions should be made, and social responsibility in testing availability are critical.

2. Self-assessment and values clarification exercises may be used to assist students in understanding their own beliefs, values, and biases and how these affect their counseling relationship with 
patients. These exercises can also be used as a model for assisting patients in self-assessment when making difficult decisions. Selfawareness exercises are often discussed in clinical psychology resources (Burnard, 1989). Values clarification exercises have been published in a variety of articles and texts (Doukas and McCullough, 1991; Simon et al., 1972).

3. Decision-making theory and practice are important components to graduate curricula. Moral reasoning is also a component of decision-making theory that may be provided through medical ethics coursework.

4. Curricula should also include risk perception and assessment. These topics, as well as health belief models, appear in the nursing and public health literature.

5. Family systems resources address the issue that individuals face decisions within a network. Family systems theory and practice are available within clinical psychology or marriage and family therapy coursework and may serve as adjunct curricula.

6. Use of language in the counseling relationship is an additional topic for updating curricula (Rapp, 1993).

7. Focus on client-centered counseling as a framework for understanding non-directiveness is useful.

8. Teaching the value of diversity as an enhancement to graduate curricula may be accomplished through community placements, coursework on the sociology of disability, and through case discussion and evaluation within student seminars. Exercises developed by the Biological Sciences Curricula Studies may stimulate discussion of issues of diversity (1992).

\section{GENETIC DISCRIMINATION}

\section{Background Discussion}

Discrimination based on one's genetic constitution, whether resulting in a symptomatic condition, a presymptomatic condition, or a carrier state has been documented (Billings et al., 1992). Questions about the proper uses of genetic information, particularly decisions about insurance coverage, employment, and access to medical care are predicted to increase. Concerns about patient confidentiality and rights to privacy will also expand with the availability of genetic testing. Genetic counseling students should be encouraged to think critically about these issues so that they can contribute to definitions of standards of care and further assist patients in the decisionmaking process. 
The definitions of privacy vs. confidentiality, knowledge of legislative structures, professional liability, public health, variation in disorders, the financial aspects of genetic disease, and the history of eugenics are all important issues related to discrimination. There is a need for a consensus statement by practicing genetic counselors and appropriate curricula for students on these issues. This could be accomplished by a survey of practicing counselors regarding current problems in genetic discrimination, the development of tools to foster awareness of personal biases, and the development of defined follow-up protocols to assess the impact of genetic information on the patient.

Privacy is clearly defined in legal terms, with support from the President's Commission (1983) as well as public and legal policies. There is less consensus on the definition of the related issue of confidentiality. Students should be instructed specifically about what other individuals have a right to know about patients, as opposed to relying on often held beliefs about what should or seems to be confidential information.

The uniqueness of genetic information as compared to other medical information should be further considered. Some medical conditions have a family-based impact comparable to genetic disorders or genotypes, but the reproductive impact of genetic disease and the cultural, community, and familial impressions or stigma of genetic conditions distinguish them from other disorders. Due to the familial context of genetic disorders and genotype, consideration should be given to ethical issues of withholding information from family members. While this is not a new issue, it is worthy of new emphasis with the increasing use of molecular diagnostic testing.

Genetic information or identity may be protected as a civil right and thus provides a framework for considering discrimination issues. Familiarity with the Americans with Disabilities Act and other legal rights for patients are pertinent to the role of counselors as advocates. In addition, there are obligations to counsel patients thoroughly about options surrounding testing. A lawsuit was recently filed because the claimant alleged that an extreme negative outcome of testing was not discussed by a counselor, resulting in a choice not to undergo testing and the birth of an affected child (Annas and Elias, 1991).

Genetic testing may lead to discrimination in health or life insurance eligibility. Individuals who are diagnosed with particular conditions, found to have a predisposing genotype, or simply found to be carriers for a recessive condition, may lose access to medical insurance. Individuals may thereby risk their job security and personal mobility because of a real or perceived pre-existing condition. For practicing genetic counselors, most information about the insurance industry, federal funding agencies and 
hospital financial policies has been gained through experience. The vast array of types of third-party coverage, use of CPT codes, and other aspects of financing genetic services can present roadblocks to providing adequate, well-informed counseling.

The history of genetic discrimination begins with the eugenics movement. Genetic counselors may be viewed as instruments for promoting a new eugenics. Individual counselors should develop a clear view of her or his role in the new testing environment. The profession should also consider how genetic technology is offered, a clear definition of the goals of testing, and the counselor's role in implementation.

The individual's concept of self in the context of genetic disease (symptomatic, presymptomatic, or carrier) is directly affected by genetic discrimination. Education by counselors regarding notions of disease variability, penetrance, and mutual genetic vulnerabilities in the population may assist in combating current and future discrimination.

\section{Recommendations for Curricula Enhancement}

1. Genetic discrimination should be discussed, and similarities and differences between genetic and other forms of discrimination should be discussed.

2. Confidentiality should be formally defined and discussed, and differences between privacy and confidentiality should be emphasized. This should include how confidentiality can best be maintained. Students should be aware of the need to communicate potential uses and/or misuses of genetic information before testing is undertaken, and of policies regarding breach of confidentiality. Role play of scenarios where confidential information is leaked may be useful to increase sensitivity and awareness of issues on both sides of this topic.

3. The value of privacy of genetic information should be debated, with focus on the flow of genetic information through the medical system from basic research to clinical implementation, the medical model as an access point for patients and its limitations, strengths, and potential for generation of conflict among family members, and the issues of ownership of an individual's testing information.

4. Curricula should include debate of the unique aspects of genetic information. Tools in the psychology literature for assessment of personal well-being and response to medical information may be used for exploration of these issues, perhaps in the context of a research methods course. The ability to perform presymptomatic 
diagnosis is another unique aspect of genetic disorders, from both a medical and a psychosocial perspective, and should be examined.

5. Acquiring basic knowledge of the legislative structure, relevant laws, and risks of liability is essential for students. This includes a focus on the obligation to inform patients of all possible tests and outcomes. Guest lecturers from a law school, attendance at professional genetics workshops, or coursework offered by other departments may assist in instruction in these areas.

6. Presentations on the financial and business aspects of medical genetics should be a formal component of training, including information about test development and costs to patients, impact on insurability, and other life decisions.

7. The process by which information on genetic disorders and tests is generated should be an area of research and curriculum development. Instruction in creating balanced presentations of information on disabilities and the variation in how persons are affected with genetic disorders should be offered. Support group members should participate in this process because of their personal experience with disorders and genetic testing decision-making.

8. The history of the field of genetic counseling, of biotechnology, and of eugenics should be incorporated into counselor training. Examples of eugenic practices from the past and the present should be presented along with current and past manifestations of genetic discrimination.

9. Policy issues, including the effects of genetic information on patients, risk of liability if patients are not fully informed of all potential outcomes, and the extent of information that must be provided to patients should all be formally addressed.

10. Methods for teaching the variation in genetic conditions, including variable expression, penetrance, and the social implications of being a gene-carrier should be explored.

\section{POTENTIAL NEW THREATS TO NON-DIRECTIVENESS}

\section{Background Discussion}

Identification of disease causing genes together with improved technological ability, and increased utilization of genetic testing by non-genetics professionals, may pose a threat to a basic tenet of genetic counseling: nondirectiveness. This prediction is based on the inevitable shortage of genetics professionals, the incorporation of genetics into all aspects of medicine and primary practice, and the probable marketing of gene testing to primary 
care providers by commercial laboratories. Genetic counselors have an opportunity both to consult and provide professional education because non-genetics medical practitioners have much to learn about genetics and the interpretation of testing. Primary care providers generally give medical advice to their patients rather than practice non-directiveness. Although shared decision-making in health care is becoming more prevalent, a nondirective stance is viewed as foreign to most primary care providers. Input from genetic counselors into uses of genome research may have an impact on the preservation of non-directiveness and therefore autonomous reproductive decision making.

Proposed changes in service delivery are also relevant to issues of informed consent. Primary care providers are likely to offer a variety of tests in busy office settings, but it is not known if this will be accompanied by appropriate counseling, opportunity for decision making, or adequate informed consent. These activities are not only time-consuming, but costly and poorly reimbursed. As testing becomes more widely available and complex, so will the informed consent process. Genetic counselors will play a role in consulting to provide some of these services, in the training of primary care providers, and in the development of educational materials. This is a critical time for counselors to be involved in the development of educational programs, to conduct research in these areas, and to further establish the profession as an essential component of an expanded mode of service delivery. In establishing recommendations for enhanced graduate curricula, review of the history and controversies regarding the practice of non-directiveness is important.

Non-directiveness is an integral component to genetic counseling whose origins lie in response to the early twentieth century eugenic movement, client-centered psychotherapy (Rogers, 1951), and a shift in medicine toward greater patient advocacy. Sheldon Reed (1955) describes the process of avoiding explicit or implicit influence on reproductive behavior that has come to be called non-directiveness. Yet, the term is too limited and nonspecific to describe interactions with patients and has lead to debate about how it is practiced (Clarke, 1991; Kessler, 1992). The seductive nature of technology may tempt counselors to offer new genetic tests; however, what is offered to patients is indeed a form of recommendation (Wilfond, 1992).

Direct messages may be projected to patients when facts are transmitted during a session and/or during exploration of their impact. The use of balanced information and less value laden language, and non-judgmental psychosocial counseling techniques should be considered when assessing nondirectiveness in practice. Euphemisms and terms in language, like "defective gene" or "special needs child" convey meaning. In a recent article, Lippman 
and Wilfond (1992) describe the phenomenon they refer to as "twice told tales," i.e., information that is provided to a couple at the time of prenatal testing may differ from how similar information is presented at the time of delivery. How facts are presented may impact significantly the choices patients make.

Client-centered therapy represents a fundamentally non-directive mode of counseling. Yet, within the counseling relationship, implicit directives may also be communicated. Careful clinical supervision and case feedback is essential to clarify these issues with individual students and professionals. These represent areas of much needed research in the field.

Alternative models to non-directiveness exist and should be considered as well. There may be instances when genetic counselors are being non-directive but should provide some direction. (An example may be in the refusal to offer a genetic carrier test to a minor at the request of the parents.) Emanuel and Emanuel (1992) discuss four physician-patient relationships: paternalistic, informative, interpretive, and deliberative. The interpretive model of shared decision-making parallels many issues in the genetic counselor-patient relationship but implies some direction is given. Arras (1984) suggests that the professional enter into dialogue with the patient to explore the underlying assumptions of the patient's values. Review of alternative approaches may help create a more universal understanding of non-directiveness in the counseling relationship, as well as establish a more satisfying vocabulary for teaching this principle.

Breach of confidentiality should be considered in any discussion of non-directiveness because it represents a paternalistic decision to overturn the rights of the patient. It is important to determine when a patient's right to confidentiality and autonomous decision-making should be superseded by an obligation to other family members. The Tarasoff case (1976) provides legal precedent for suggesting that confidentiality should be breached when there is a potential for grave harm to a third party.

A re-definition of the genetic counseling process, centering on the issue of non-directiveness, would enhance the teaching of non-directiveness. Clarification of the objectives of the practice of non-directiveness would have widespread implications for all levels of graduate education.

\section{Recommendations for Curricula Enhancement}

1. Development of a consensus in the profession on the definition of non-directiveness, its goals and importance. Graduating professionals 
should be prepared to debate this issue, form an operating definition, and incorporate it into a mode of practice.

2. Students and counselors should be encouraged to pursue research into non-directiveness and use the results to update curricula. Because non-directiveness is a central principle in genetic counseling, results will have implications for all levels of curricula, particularly clinical application.

3. Critical evaluation of counseling and communication skills should be performed through the use of videotaping, clinical supervision, and interactive computer programs.

\section{GENETIC SCREENING IMPLEMENTATION AND POLICY DEVELOPMENT}

\section{Background Discussion}

The implementation of genetic screening, for example for cystic fibrosis, is controversial (Wilfond and Fost, 1990; Scriver and Fujiwara, 1992). As a result of the Human Genome Initiative, more tests for presymptomatic states and carrier states will become available. Decisions regarding implementation of screening, timing of screening (prenatal, newborn, adolescence, or adulthood), appropriate settings, accompanying education, and counseling protocols will need to be resolved. The release of research tests into the clinical setting, development of guidelines, and goals of screening will demand input from the genetic counseling community. Genetic counseling graduates should be prepared to participate in these discussions and policy determination. Thus, in making recommendations for graduate programs, suggestions for the National Society of Genetic Counselors were developed as well.

Graduate preparation should include knowledge and skills in the areas of basic science and technology of human genome research, familiarity with public health and advocacy organizations, understanding of quality assurance, and the principles of ethical decision-making.

Both students and practicing counselors should remain abreast of genome research, current technology, DNA testing, and screening programs. Accurate information regarding availability of clinical testing services is essential. To this end, development and dissemination of publications on laboratory services would be useful (Faucet, 1990).

In developing recommendations for graduate programs, a number of ideas were generated for practicing genetic counselors. As the most logical means for generating dialogue and action on these issues, they have been submitted to the Education Committee of the National Society of Genetic 
Counselors (NSGC) for further consideration. A summary of these recommendations includes: active involvement in information management and creation of educational materials for public and professional use; establishment of a resource database of continuing education opportunities; publication of the work of counselors who serve on task forces or policymaking committees; further professional liaison with the Alliance of Genetic Support Groups office staff; development of position papers on universal health care and genetic screening programs. The latter would parallel the American Society of Human Genetics' position paper on cystic fibrosis population screening (Caskey et al., 1990). Both efforts would further establish the active role genetic counselors may play in policy decisions. The profession would be well served by taking a lead role in such activities and deliberations.

There is a need to foster the unique relationship between counselors and their patients in the context of expanded testing and screening. Genetic counselors should represent the needs of patients, understand the impact of genetic information on their lives and learn about the legislative role of advocacy groups through open exchange with consumers of genetic services. These views may then be more rapidly assimilated into testing and screening service and policy development.

\section{Recommendations to Enhance Curricula}

1. Students should demonstrate understanding of molecular genetics and interpretation of results of testing, as listed under Genetic Laboratory Methods of the endorsed minimal guidelines for training programs (Walker et al., 1990).

2. Significant emphasis should be placed on the need for student awareness of public policy development regarding genetic screening. Many programs currently include curricula in public health with coursework in health care policy development. This is also listed in the previously endorsed guidelines for graduate education in genetic counseling (Walker, et al., 1990).

3. All counselors and students should be encouraged to contribute to the development of position papers on social issues and to communicate their involvement in local, regional, and national political and public policy activities.

4. Outreach rotations for students with a legislative focus should be considered for those who show interest in this area of genetic policy development. 
5. Alliances between the NSGC, graduate programs, and national support groups should be investigated for student educational roles and summer internships.

6. Program directors and other counselors who are actively participating in genetics public policy organizations should share information with students, foster student participation, and establish a mentoring role.

7. Student education should include mechanisms to address quality assurance issues, related to both laboratory-based and counseling-based activities.

8. Medical ethics should be a component of all graduate programs. Publication of clinical cases demonstrating important ethical issues should be encouraged for students and practicing counselors. The use of case-based teaching and role playing can also facilitate this coursework.

9. Didactic work in public health may also be supplemented through formal internships with genetic counselors who serve as state genetics service coordinators, with lobbyists at either the state or federal level, and through federal agencies involved in genetics policy.

\section{CONCLUSION}

Advancing technology in human genetics is resulting in new roles and responsibilities for genetic counselors. As a consequence, graduate education programs have been given the task of preparing future professionals for positions that are still in the process of evolving. This includes providing a substantial knowledge base so that future genetic counselors can assimilate and present to their patients information regarding newly developed molecular tests. Equally important, however, is student awareness of the social, psychological, and ethical implications of this technology.

While the challenge of providing this multifaceted education is imposing, the future of the genetic counseling profession is dependent on these efforts. Educators should be prepared to respond to increasing requirements for adequate professional preparation as the field demands. The recommendations developed by genetic counseling program directors, invited experts, and NSGC Education Committee members present at Asilomar are only a beginning. It is hoped that they will serve as a basis for debate, dialogue, and continued development of graduate curricula in genetic counseling. 


\section{ACKNOWLEDGMENTS}

This work was supported by a grant from the National Center for Human Genome Research, National Institutes of Health-HG00738. The authors would like to thank all of the participants in the 1992 NSGC Asilomar conference, specifically the invited speakers who so generously contributed their expertise. In particular, we would like to acknowledge the extensive input into the workshop discussions by Drs. Paul Billings and Benjamin Wilfond. Much of the tone, issues, and references resulted directly from their role as facilitators. We are also grateful to Dr. Leslie Biesecker for his constructive review and comments on this manuscript.

\section{APPENDIX}

The case scenarios presented below were used to stimulate discussion in the workshops at the 1992 Asilomar Conference and are published here as ideas for case-based teaching for graduate instructors or practicing counselors.

\section{Case for Workshop on Human Variation}

It is 1999. Specific genes have now been characterized which predispose a child to learning disabilities. No good treatment has become available, other than more focused intervention from the school system (which is a bit better than what is currently available for addressing the needs of children who are affected). Some obstetricians have added this DNA testing to a panel of tests they are routinely offering to their pregnant patients. The media has written several provocative articles about the availability of the testing, so more and more patients are inquiring about it. A few genetic prenatal diagnostic centers are also offering the testing, but there is no standard of practice consistently upheld across the country.

\section{Discussion Questions:}

What stance should genetic counselors take regarding this test option?

Should prenatal counselors raise it as an option with all patients?

Should counselors offer it only to those who request it?

Should counselors refrain from discussing it with patients?

Should counselors refuse to offer it as an option? 
How should a counselor make such a decision regarding the offering of a test? What should be considered?

Does this scenario challenge the value of non-directiveness? If so, in what ways?

How does such testing challenge counselors' ideas about human variation? What constitutes a trait? How does it affect our ideas about disability or mental handicap?

\section{Cases for Workshop on Genetics Discrimination}

Case 1: There was a gentleman who had been diagnosed as having myotonic dystrophy both by family history and by minimal physical changes (very mild cardiomyopathy). He applied for and received life insurance despite an assessment which included review of his medical records. In response to a question about whether he had any significant debilitating conditions he answered no. He was essentially asymptomatic from his condition, and did not consider himself to be critically ill. This gentleman subsequently died in an automobile accident and his family filed a claim with the insurance company. The company refused to pay the claim, saying that he had fraudulently obtained the insurance. The family sued the company, and the court case was settled in favor of the insurance company.

Case 2: Mr. $\mathrm{X}$ is a 40-year-old Caucasian male who has a daughter with Marfan syndrome. Twenty years ago, Mr. X dissected an aortic aneurysm but survived. At that time he was told that he might have Marfan syndrome. Over the subsequent years, $\mathrm{Mr}$. $\mathrm{X}$ has received no treatment for this disorder, has not been ill, and has never had a discussion with his physician concerning his condition or any other significant problem. Mr. X applied for a short-term health insurance policy for which he released his old records and filled out the forms accurately and truthfully. No questions were asked about his past medical health. This policy has a pre-existing exclusion for conditions which the client was being treated or ought to have been treated over the 5 years prior to the policy period. Shortly after being accepted into the insurance program, $\mathrm{Mr}$. X dissected a thoracic aneurysm incurring a $\$ 250,000$ hospital bill. His insurance company refused to pay, claiming that his hospital bills represented a cost related to a pre-existing condition. Litigation was initiated. 
Discussion Questions:

What are the legal and ethical considerations in each case (for the patient, for the company)?

How can issues of self-determination, concept of self, confidentiality, and patient autonomy be reconciled with the existing legal framework?

How would you as a counselor handle questions from such a patient as depicted in case 1 regarding completion of insurance forms?

\section{Case for Workshop on New Threats to Non-Directiveness:}

It is the year 2010. There has been a paradigm shift in the provision of genetic services so that priority is given to issues for the public good (rather than individual autonomous decision making), as a result of limited medical and third-party payer resources. Prenatal diagnosis for cystic fibrosis, Marfan syndrome, muscular dystrophy, polycystic kidney disease, and neurofibromatosis have become routine in the general population since the automation of direct DNA testing. The rate of termination of pregnancy when a disorder is detected is approximately $95 \%$. It has become routine for counselors to witness these outcomes and therefore, less attention seems to be paid to non-directive counseling. Terminations are recommended by counselors in some circumstances, although if a patient chooses to continue a pregnancy, nothing is done to dissuade her.

\section{Discussion Questions:}

How does this scenario compare to current practices? Are there circumstances when counselors make decisions to act in a more directive manner? Is this acceptable? Should counselors ever recommend termination of pregnancy?

How does the "recommendation" in this scenario differ from issues of "offering" termination as an option as is commonly discussed? How are students taught such differences?

What rights does the unborn child have in this scenario? How do they impact on "the public good?" Who is the advocate for the fetus?

How might genetic counselors help to influence or define a paradigm shift in the delivery of services? How are students trained to think in this matter? 


\section{Population Screening}

\section{Case for Workshop on Population Screening}

DNA-based testing has become clinically available which deter- mines whether an individual has an inherited predisposition to development of cancer (i.e., not a $100 \%$ chance even if the gene in question is inherited). Insurance companies are anxious for rapid implementation of early screening and many primary care physicians see the potential benefits in terms of behavior modification and prophylactic therapy.

\section{Discussion Questions:}

What patient advocacy issues are involved in this scenario?

What are the possible benefits and potential costs of this type of information, and how do counselors assist the patient in weighing the two?

Should genetic counselors take an active role in development of policies related to this type of screening?

What are the ethical issues encountered in this case?

\section{REFERENCES}

Annas GJ, Elias S (1991) Remodeling legal standard setting for genetic screening and counseling. Am J Hum Genet Suppl 49:209 (Abstr).

Arras J (1984) Toward an ethic of ambiguity. Hastings Center Rep 4(2):25-33.

Billings PR, Kohn MA, de Cuevas M, Beckwith J, Alper JS, Natowicz MR (1992) Discrimination as a consequence of genetic testing. Am J Hum Genet 50:476-482.

Burnard P (1989) Counseling Skills for Health Professionals. New York: Chapman and Hall.

Caskey CT, Kaback MM, Beaudet AL (1990) The American Society of Human Genetics statement on cystic fibrosis screening. Am J Hum Genet 46:393.

Clarke A (1991) Is non-directive genetic counseling possible? Lancet 338:998-1001.

Cutter MA, Drexler E, McCullough LB, McInerney JD, Murray JC, Rossiter B, Zola J (1992) Mapping and Sequencing the Human Genome: Science, Ethics and Public Policy. Biological Science Curriculum Study, Colorado Springs and American Medical Association, Chicago.

Doukas DJ, McCullough LB (1991) The values history. J Fam Prac 32(2):145-153.

Emanuel EJ, Emanuel LL (1992) Four models of the physician-patient relationship. JAMA 267:2221-2226.

Faucet A (1990) Learn your labs. Perspec Genet Couns 12:1,4.

Helix, National Directory of DNA Diagnostic Laboratories. Children's Hospital and Medical Center, P.O. Box 5371, CH-94, 4800 Sand Point Way, NE, Seattle, WA 98105-0371. (206) 528-2689 or FAX (206) 528-2687.

Jones OD (1992) Sex selection: Regulating technology enabling the predetermination of a child's gender. Harv $J$ Law and Tech 6:1-62.

Kessler S (1992) Psychological aspects of genetic counseling. VII. Thoughts on directiveness. $J$ Genet Couns 1:9-17. 
Lippman A, Wilfond BS (1992) Twice-told tales: Stories about genetic disorders. Am J Hum Genet 51:36-37.

Nelkin D (1993) Genetic Metaphors and Their Popular Appeal. AAAS Meeting Presentation, Washington DC.

Rapp R (1993) Amniocentesis in sociocultural perspective. J Genet Couns 2:xxx-xxx.

Reed SC (1955) Counseling in Medical Genetics. Philadelphia: WB Saunders Company.

Rogers CR (1951) Client-Centered Therapy: Its Current Practice, Implications and Theory. Boston: Houghton Mifflin.

Scriver CR, Fujiwara FM (1992) Invited editorial: Cystic fibrosis genotypes and views on screening are both heterogeneous and population related. Am J Hum Genet 51:943-950.

Simon SB, Howe LW, Kirschenbaum H (1972) Values Clarification. New York: Hart Publishing Company.

Tarasoff vs. Regents of the University of California (1976) 131 Cal. Rptr. 14, 17 Cal. App. 3d 425, 551 P.2d 334.

U.S. President's Commission for the Study of Ethical Problems in Medicine and Biomedical and Behavioral Research (1983) Screening and Counseling in Genetic Conditions: The Ethical, Social and Legal Implications of Genetic Screening, Counseling and Education Programs. US Government Printing Office, Washington, DC.

Walker A, Scott JA, Biesecker BB, Conover E, Blake W, Djurdjinovic L (1990) Report of the 1989 Asilomar meeting on education in genetic counseling. Am J Hum Genet 46:1223-1230.

Wertz DC, Fletcher JC (1988) Attitudes of genetic counselors. Am J Med Gen 42:592-600.

Wilfond BS (1992) Unpublished communication, 1992 Asilomar conference.

Wilfond BS, Fost N (1990) The cystic fibrosis gene: Medical and social implications for heterozygote detection. JAMA 263:2777-2783. 